\title{
Gas-abrasive wear resistance of silicon and boron carbonitride films
}

\author{
V. R. Shayapov ${ }^{1, \dagger}$, V.S. Sulyaeva ${ }^{1}$, Yu. M. Rumyantsev ${ }^{1}$, M. N. Khomyakov ${ }^{2}$, M. L. Kosinova ${ }^{1}$ \\ †'shayapov@niic.nsc.ru
}

${ }^{1}$ Nikolaev Institute of Inorganic Chemistry, Siberian Branch of RAS, 3 Acad. Lavrentiev Ave., 630090, Novosibirsk, Russia ${ }^{2}$ Institute of Laser Physics, Siberian Branch of RAS, 13/3 Acad. Lavrentiev Ave., 630090, Novosibirsk, Russia

Gas-abrasive wear resistance of silicon carbonitride $\mathrm{SiC}_{x} \mathrm{~N}_{y} \mathrm{H}_{z}$ and boron carbonitride $\mathrm{BC}_{x} \mathrm{~N}_{y}$ films obtained by chemical vapor deposition (CVD) method was studied. Wear resistance tests were carried out in a flux of sand particles falling on the samples under the gravity action. Scanning electron microscopy, scanning probe microscopy, ellipsometry and spectrophotometry were used to detect the surface modifications occurred during this treatment. In addition, early published data on the physical and chemical properties of the films are involved for interpreting the results of gas-abrasive tests. The $\mathrm{SiC}_{x} \mathrm{~N}_{y} \mathrm{H}_{z}$ films were obtained by plasma-enhanced CVD from the mixture of hexamethyldisilazane vapor and helium at deposition temperatures $100-800^{\circ} \mathrm{C}$ and pressure 0.05 Torr. It was found that gas-abrasive wear resistance of the films increased with the deposition temperature due to the changes in a chemical composition of the films towards the hard $\mathrm{SiC}_{x} \mathrm{~N}_{y}$ material. $\mathrm{BC}_{x} \mathrm{~N}_{y}$ films were synthesized by low-pressure CVD from triethylamine borane vapor and its mixture with ammonia (ratio of partial pressures $1: 1)$. Deposition temperature was $700^{\circ} \mathrm{C}$. There is a difference in destruction mechanisms of the films deposited from these compositions of the initial gas mixture. The surface of films synthesized from triethylamine borane vapor and treated with sand particles shows destroyed and undamaged areas similar to the $\mathrm{SiC}_{x} \mathrm{~N}_{y} \mathrm{H}_{z}$ films. When ammonia is added to the initial gas mixture, the surface of the treated films acquires a specific appearance with lots of scratches. These changes are associated with a decrease in the hardness and Young's modulus of the $\mathrm{BC}_{x} \mathrm{~N}_{y}$ films due to the nitrogen concentration enhancement.

Keywords: gas-abrasive wear resistance, carbonitride, chemical vapor deposition, roughness, spectrophotometry.

\section{Газоабразивная износостойкость пленок карбонитридов кремния и бора}

\author{
Шаяпов В. Р. ${ }^{1, \dagger}$, Суляева В. С. ${ }^{1}$, Румянцев Ю. М. ${ }^{1}$, Хомяков М. Н. ${ }^{2}$, Косинова М. Л. ${ }^{1}$
}

${ }^{1}$ ИНХ СО РАН, пр. Академика Лаврентьева 3, 630090, Новосибирск, Россия

${ }^{2}$ ИЛФ СО РАН, пр. Академика Лаврентьева 13/3, 630090, Новосибирск, Россия

Проведено исследование газоабразивной износостойкости пленок карбонитридов кремния $\mathrm{SiC}_{x} \mathrm{~N}_{y} \mathrm{H}_{z}$ и бора $\mathrm{BC} \mathrm{N}_{y}$, полученных в процессах химического осаждения из газовой фазы. Испытания на износостойкость проводились в потоке частиц песка, падающих на образец под действием силы тяжести. Для обнаружения возникших при такой обработке изменений поверхности использованы методы сканирующей электронной микроскопии, сканирующей зондовой микроскопии, эллипсометрии и спектрофотометрии. Также для интерпретации результатов газоабразивных испытаний привлечены ранее опубликованные данные по физико-химическим свойствам пленок. Плёнки $\mathrm{SiC}_{x} \mathrm{~N}_{y} \mathrm{H}_{z}$ получены в процессе плазмохимического осаждения из паров гексаметилдисилазана в смеси с гелием, при температуре осаждения от 100 до $800^{\circ} \mathrm{C}$ и давлении 0,05 мм рт. ст. Найдено, что с ростом температуры осаждения наблюдается увеличение газоабразивной износостойкости пленок, обусловленное изменением химического состава пленок в сторону твердого материала $\mathrm{SiC}_{x} \mathrm{~N}_{y}$. Пленки $\mathrm{BC}_{x} \mathrm{~N}_{y}$ получены методом термического осаждения при пониженном давлении из паров триэтиламинборана и его смеси с аммиаком (отношение парциальных давлений $1: 1)$. Температура осаждения $-700^{\circ} \mathrm{C}$. Обнаружено отличие механизмов разрушения пленок, осажденных при этих составах исходной газовой смеси. Поверхность пленок, синтезированных из паров триэтиламинборана, после обработки частицами песка имеет разрушенные и уцелевшие участки, подобно пленкам $\mathrm{SiC}_{x} \mathrm{~N}_{y} \mathrm{H}_{z}$. При добавлении аммиака в исходную газовую смесь поверхность обработанных пленок приобретает специфический вид с множеством царапин. Такие изменения связываются с уменьшением твердости и модуля Юнга пленок $\mathrm{BC}_{x} \mathrm{~N}_{y}$, обусловленным увеличением содержания азота в пленках.

Ключевые слова: газоабразивная износостойкость, карбонитрид, химическое осаждение из газовой фазы, шероховатость, спектрофотометрия. 


\section{1. Введение}

В настоящее время поиск и исследование новых функциональных материалов, обладающих высокой твердостью, износостойкостью, термической и химической стойкостью, является важнейшей задачей современного прикладного материаловедения в авиационной и ракетной технике. Еще одно важное направление - получение защитных покрытий на солнечных элементах и оптических изделиях. Изучение газоабразивной эрозии под действием ударов твердых частиц чрезвычайно важно при разработке новых типов таких покрытий. Особенно это актуально при использовании в условиях, где неизбежно наличие твердых частиц естественного происхождения в потоке жидкости или газа. Типичный пример - нефтегазовая отрасль [1]. Для солнечных элементов характерны условия эксплуатации вне помещений. Как следствие, они подвергаются воздействию потоков твердых частиц, переносимых ветром. Особое значение эта проблема приобретет в пустынях, которые рассматриваются как наиболее перспективные территории для создания крупнейших солнечных электростанций огромной мощности, достаточной для решения проблем электроснабжения на глобальном уровне [2]. Оптические покрытия также могут подвергаться абразивному истиранию и требуют особого контроля износостойкости [3]. Кроме того, современное состояние средств автоматики и прецизионного программируемого управления газовыми потоками позволяет распространить методику обработки материалов в газоабразивном потоке на задачи, отличные от простого испытания на износостойкость. Например, это могут быть задачи послойного анализа, формирования управляемой шероховатости, выявления микроскопического контраста в композитных системах и др.

В последние десятилетия газоабразивное изнашивание различных пленок и покрытий широко исследуется [4-8]. Тем не менее, проблема выбора критериев износа остается весьма актуальной. Как правило, в качестве критериев износа используются характеристики, связанные с потерей массы или объема обработанного материала. Например, в [4] предлагается выражение для описания скорости изнашивания (отношение потери массы пленки к общей массе частиц эродента) через отношение твердостей мишени и эродента, возведенное в степень с эмпирическим показателем. Существуют и другие математические модели газоабразивного изнашивания, в том числе, не использующие величины твердостей мишени и бомбардирующих частиц [5-7]. Очевидно, что эти модели не универсальны: они существенно зависят от эмпирических параметров и функций, которые зачастую сложно точно определить. В общем случае модель явления газоабразивного изнашивания крайне сложна [1].

Часто для изучения газоабразивного изнашивания покрытий используются струйные методы испытания, когда образец подвергается воздействию ускоренного потока твердых частиц. В [1] отмечается, что этому способу испытаний присущ ряд недостатков, главный из которых - испытание не воспроизводит реальных условий износа. В данной работе применяется метод испытания на газоабразивный износ, основанный на движении твердых частиц песка под действием силы тяжести.

Цель настоящей работы - исследование газоабразивной износостойкости пленок карбонитридов кремния $\mathrm{SiC}_{x} \mathrm{~N}_{y} \mathrm{H}_{z}$ и бора $\mathrm{BC}_{x} \mathrm{~N}_{y}$, полученных в процессах химического осаждения из газовой фазы. Пленки карбонитрида кремния синтезируются методом плазмохимического осаждения (Plasma-enhanced chemical vapor deposition - PECVD) из паров кремнийорганических соединений и, в зависимости от температуры осаждения, имеют широкий диапазон составов и свойств от полимероподобных до твердых композитных. Пленки карбонитрида бора образуются в процессе термического осаждения из газовой фазы при пониженном давлении (Low-pressure chemical vapor deposition - LPCVD). B качестве исходных соединений применяются борорганические соединения, в частности, алкиламинбораны. Пленки $\mathrm{BC}_{x} \mathrm{~N}_{y}$ представляют собой высокотвердые (до 30 - 40 ГПа) покрытия [9]. Результаты исследования газоабразивной износостойкости сопоставлены с полученными ранее данными по механическим свойствам, составу и структуре пленок [9-13]. Значительное внимание уделено проблеме выбора критериев износа на основе результатов физико-химических исследований.

\section{2. Экспериментальная часть}

Установка для проведения испытаний на газоабразивную износостойкость представляет собой вертикальную стеклянную трубку высотой 65 см с емкостью объемом 150 мл для абразива (песка), расположенной сверху. Образец расположен под углом $45^{\circ}$ к потоку частиц песка [14]. Во всех экспериментах использовался один и тот же объем песка, поэтому время всех экспериментов было одинаковым и составляло около 10 мин. В работе использовался сухой песок для строительных работ ГОСТ 8736-93. Максимум функции распределения частиц по размерам приходится на 0,2-0,3 мм. Песок под действием собственной силы тяжести поступает на образец, вращающийся с небольшой скоростью. Затем песок ссыпается в приемную емкость. Несмотря на простоту устройства, эта система воспроизводима и управляема. Идея метода близка к стандартному методу испытаний лакокрасочных покрытий по ГОСТ 20811 - 75. Подобная схема испытаний применялась для исследования оптических оксидных покрытий [3], а описанная выше установка использована для определения газоабразивной износостойкости пленок $\mathrm{V}_{2} \mathrm{O}_{5}$ [14].

В данной работе изучены закономерности газоабразивного изнашивания пленок $\mathrm{SiC}_{x} \mathrm{~N}_{y} \mathrm{H}_{z}$ и $\mathrm{BC}_{x} \mathrm{~N}_{y}$. Плёнки карбонитрида кремния $\mathrm{SiC}_{x} \mathrm{~N}_{y} \mathrm{H}_{z}^{z}$ получены в процессе PECVD из паров гексаметилдисилазана $\left(\mathrm{CH}_{3}\right)_{3}$-Si-NH-Si- $\left(\mathrm{CH}_{3}\right)_{3}$ в смеси с гелием, при температуре осаждения от 100 до $800^{\circ} \mathrm{C}$ и давлении 0,05 мм рт. ст. Плёнки карбонитрида бора $\mathrm{BC}_{x} \mathrm{~N}_{y}$ синтезированы методом LPCVD из паров триэтиламинборана (ТЭАБ) $\left(\mathrm{C}_{2} \mathrm{H}_{5}\right)_{3} \mathrm{~N} \cdot \mathrm{BH}_{3}$ и его смеси с аммиаком при отношении парциальных давлений 1:1. Процессы проводились при температуре $700^{\circ} \mathrm{C}$. 
Изменения поверхности пленок до и после испытаний исследованы методами сканирующей электронной микроскопии (СЭМ), сканирующей зондовой микроскопии (С3M), а также оптическими методами эллипсометрии и спектрофотометрии. Определение шероховатости поверхностей пленок выполнялось методом силовой зондовой микроскопии с использованием системы Nanoscan-3D (ФГБНУ ТИСНУМ, Россия). Более подробно процедура измерений описана в [10]. Исследование морфологии поверхности проводилось с использованием сканирующей электронной микроскопии (СЭМ) на растровом электронном микроскопе JSM 6700F (JEOL, Япония).

Толщина и показатель преломления пленок определялись методом нулевой монохроматической эллипсометрии с использованием эллипсометра ЛЭФ-3М. Параметры поляризации отраженного света $\psi$ и $\Delta$ были измерены в диапазоне углов падения света на образец от $50^{\circ}$ до $80^{\circ}$ с шагом $5^{\circ}$, длина волны света $-632,8$ нм. Методика поиска начальных приближений и решения обратной задачи эллипсометрии представлена в работах $[15,16]$.

Измерения спектров отражения проводились с использованием спектрофотометрической системы, состоящей из спектрометра «Колибри-2» (ВМК «Оптоэлектроника», Россия), зонда отражения/обратного рассеяния QR-400-7 (Ocean Optics, США), дейтерийвольфрамовой лампы AvaLight-DHS (Avantes, Нидерланды). Спектры отражения записывались в виде величин относительного коэффициента отражения $R / R_{\mathrm{Si}}$ $(R-$ абсолютный коэффициент отражения от образца, $R_{\mathrm{Si}}$ - отражение от полированной поверхности кремния, принятое за 100\%) в спектральном диапазоне 400 - 900 нм.

\section{3. Результаты и их обсуждение}

Ранее были исследованы некоторые физико-химические свойства пленок $\mathrm{SiC}_{x} \mathrm{~N}_{y} \mathrm{H}_{z}$, полученных в интервале температур осаждения $100-800^{\circ} \mathrm{C}$ [9-12]. Показано, что при низких температурах осаждения пленки имеют полимероподобное строение, при котором пленки имеют состав, близкий к составу исходного соединения, в пленке сохраняются некоторые типы химических связей исходного соединения. Твердость таких кремнийорганических пленок весьма мала и сопоставима со значениями, характерными для полимеров [10]. С ростом температуры осаждения содержание водородсодержащих связей в пленках уменьшается, состав пленок приближается к карбонитриду кремния $\mathrm{SiC}_{x} \mathrm{~N}_{y}-$ твердому композитному материалу. По данным эллипсометрических измерений толщина пленок составляет $500-1200$ нм. Показатель преломления увеличивается от 1,5 до 2,3 с ростом температуры осаждения.

Очевидно, что указанные закономерности должны проявиться в особенностях газоабразивного изнашивания данных пленок. Методом СЗМ определена средняя арифметическая шероховатость синтезированных пленок, которая составила 2-6 нм [10]. После обработки в потоке частиц песка обнаружено значительное увеличение шероховатости пленок по сравнению с исход- ными образцами. Для пленки, полученной при $100^{\circ} \mathrm{C}$, после обработки шероховатость достигала 55 нм. С ростом температуры осаждения пленок их шероховатость уменьшалась: для плёнки $\mathrm{SiC}_{x} \mathrm{~N}_{y} \mathrm{H}_{z}$, полученной при температуре осаждения $400^{\circ} \mathrm{C}$, она составила около 25 нм, а для более высокотемпературных пленок приближалась к значениям, характерным для необработанных пленок. Это обусловлено ростом твердости пленок с увеличением температуры их осаждения. Таким образом, износостойкость можно оценивать по величине вносимой шероховатости. Этот критерий особенно важен в задачах получения и исследования пленок для оптических покрытий, так как шероховатость определяет величину рассеяния света в оптической структуре. Явления, связанные с образованием шероховатого слоя, также являются эффективными критериями износа. В частности, в [3] контролировалось изменение спектра пропускания в результате газоабразивной обработки. Для решения данной задачи могут быть использованы и спектры отражения. Особенно информативны спектры диффузной компоненты отраженного света при измерениях в фотометрическом шаре (интегрирующей сфере) с ловушкой зеркального отражения [14]. Тем не менее, для предварительных измерений можно использовать устройства на основе зондов отражения /обратного рассеяния, измеряющие полное отражение. Такой подход применялся в данной работе. Спектры относительного коэффициента отражения пленок $\mathrm{SiC}_{x} \mathrm{~N}_{y} \mathrm{H}_{z}$, зарегистрированные до испытаний, имеют типичный для систем пленка-подложка вид (рис. 1). Наблюдается чередование интерференционных экстремумов. Огибающая, проходящая через максимумы, описывает край поглощения, а в области прозрачности пленок относительные коэффициенты отражения в максимумах доходят до значения 100\%. После испытаний вид спектра пленки толщиной 1150 нм, полученной при $200^{\circ} \mathrm{C}$, такой же, как и у чистой поверхности кремния, подвергнутой испытанию (рис. 1a,b). Это свидетельствует о практически полном истирании пленки. Аналогичный результат получен для пленки толщиной 1000 нм, осажденной при $100^{\circ} \mathrm{C}$. Для пленок, износившихся частично, имеет место уменьшение «размаха» интерференционных полос за счет увеличения диффузной составляющей отраженного света. Это явление наблюдается на спектрах пленки толщиной 560 нм, полученной при $400^{\circ} \mathrm{C}$ (рис. 1с). При дальнейшем увеличении температуры осаждения изменения спектров становятся меньше. Величина изменения коэффициента отражения в рабочей спектральной области может служить критерием износа пленок. В данном случае результаты двух методов подтверждают, что износостойкость пленок $\mathrm{SiC}_{x} \mathrm{~N}_{y} \mathrm{H}_{z}$ возрастает с увеличением температуры их осаждения в изученном интервале.

Изображения сканирующей электронной микроскопии (рис. 2) позволяют определить участки пленок, подвергнутые разрушению. До испытаний изображения поверхности всех образцов были подобны: однородные, гладкие, без особенностей. После обработки проявился значительный контраст. Результаты спектрофотометрических исследований позволяют интерпретировать появившиеся после обработки более светлые области 
как области разрушения пленки. Видно, что с ростом температуры осаждения относительная площадь таких областей уменьшается, изображение поверхности пленки толщиной 1000 нм, полученной при температуре осаждения $800^{\circ} \mathrm{C}$ и подвергнутой испытанию, почти не отличается от изображения исходной, необработанной пленки.
Микроскопические изображения поверхности, подвергнутой обработке в потоке частиц песка, позволяют судить о механизме изнашивания. СЭМ изображения обработанных пленок $\mathrm{BC}_{x} \mathrm{~N}_{y}$, полученных из паров ТЭАБ и его смеси с аммиаком, имеют совершенно разный вид (рис. 3). До испытания поверхности пленок были однородными, без выраженных особенностей.

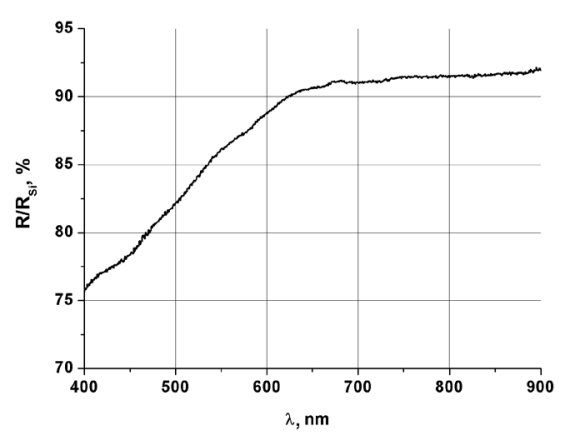

a

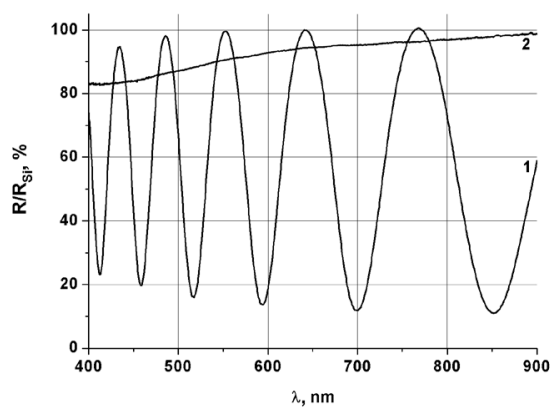

b

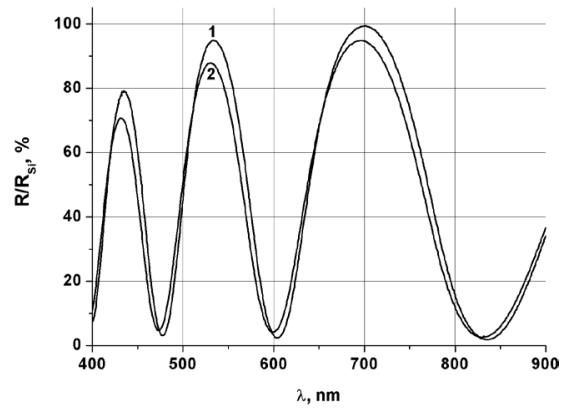

C

Рис. 1. Спектр отражения подложки кремния, подвергнутой газоабразивному испытанию (a), спектры отражения пленок $\mathrm{SiC}_{x} \mathrm{~N}_{y} \mathrm{H}_{z}$, полученных при температурах осаждения $200^{\circ} \mathrm{C}$ (b) и $400^{\circ} \mathrm{C}$ (c) до (линии 1) и после (линии 2) испытания.

Fig. 1. Reflection spectrum of silicon substrate subjected to gas-abrasive wear (a), reflection spectra of $\mathrm{SiC}_{x} \mathrm{~N}_{y} \mathrm{H}_{z}$ films obtained under deposition temperature $200^{\circ} \mathrm{C}(\mathrm{b})$ and $400^{\circ} \mathrm{C}$ (c) before (lines 1) and after (lines 2) testing.

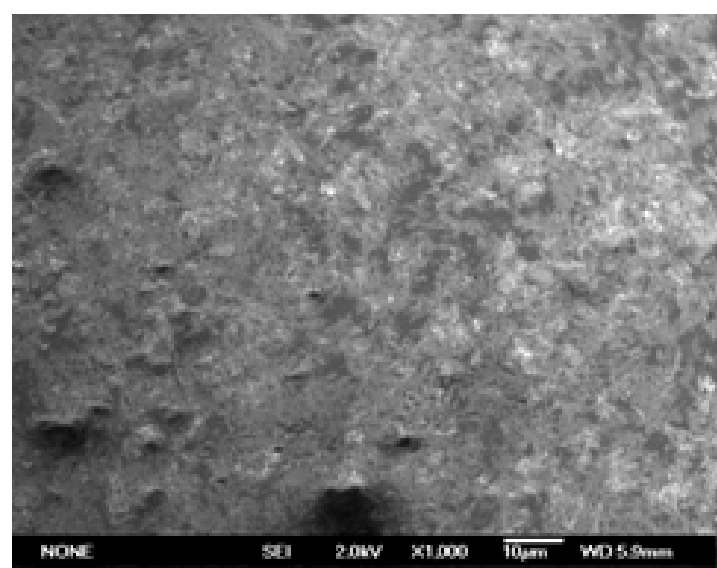

a

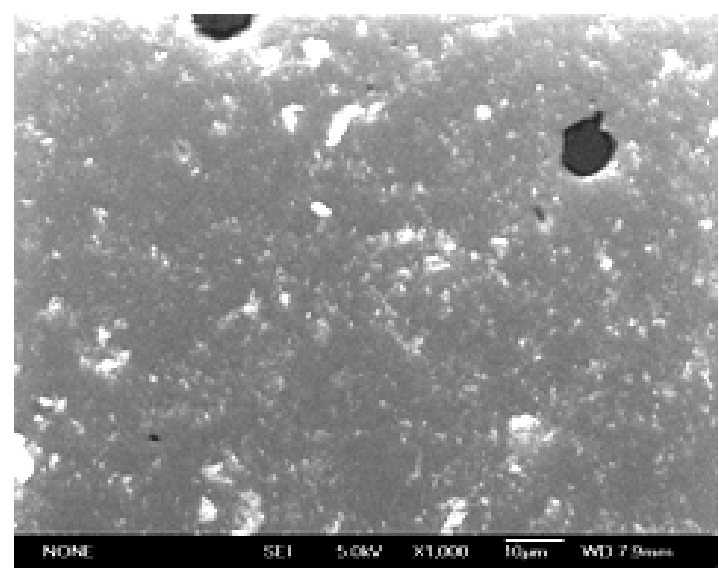

c

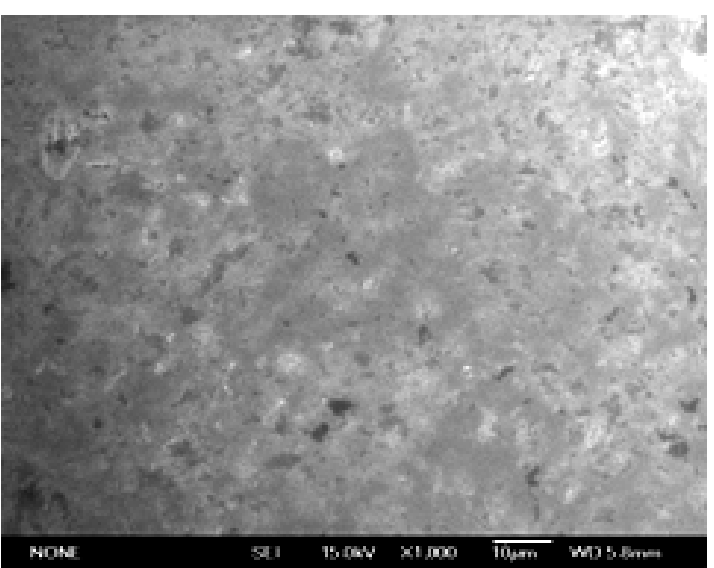

$\bar{b}$

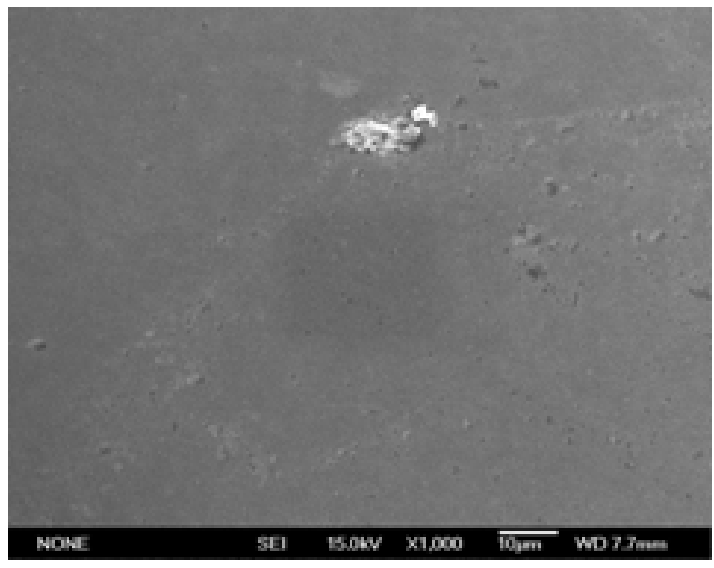

d

Pис. 2. Изображения СЭМ пленок $\mathrm{SiC}_{x} \mathrm{~N}_{y} \mathrm{H}_{z}$, полученных при температурах осаждения $100^{\circ} \mathrm{C}(\mathrm{a}), 200^{\circ} \mathrm{C}(\mathrm{b}), 400^{\circ} \mathrm{C}(\mathrm{c})$ и $800^{\circ} \mathrm{C}(\mathrm{d})$ и подвергнутых испытанию на газоабразивную износостойкость.

Fig. 2. SEM images of $\mathrm{SiC}_{x} \mathrm{~N}_{y} \mathrm{H}_{z}$ films obtained under deposition temperatures $100^{\circ} \mathrm{C}(\mathrm{a}), 200^{\circ} \mathrm{C}(\mathrm{b}), 400^{\circ} \mathrm{C}$ (c) и $800^{\circ} \mathrm{C}$ (d) and subjected to gas-abrasive wear testing. 


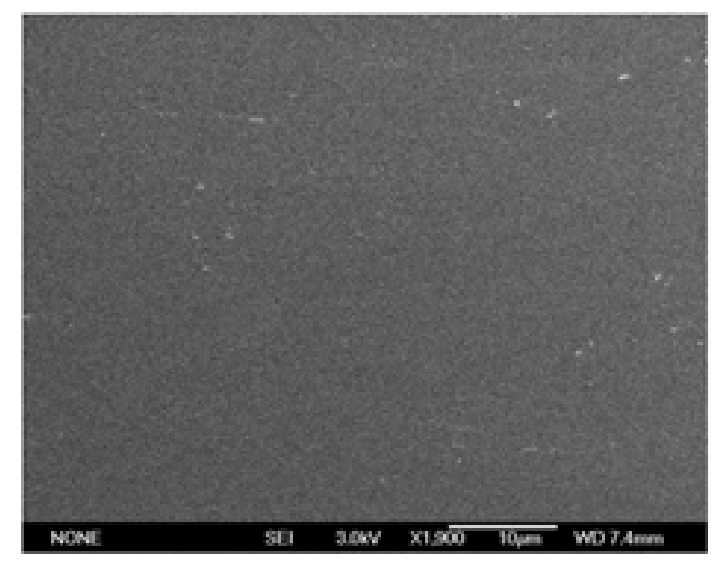

a

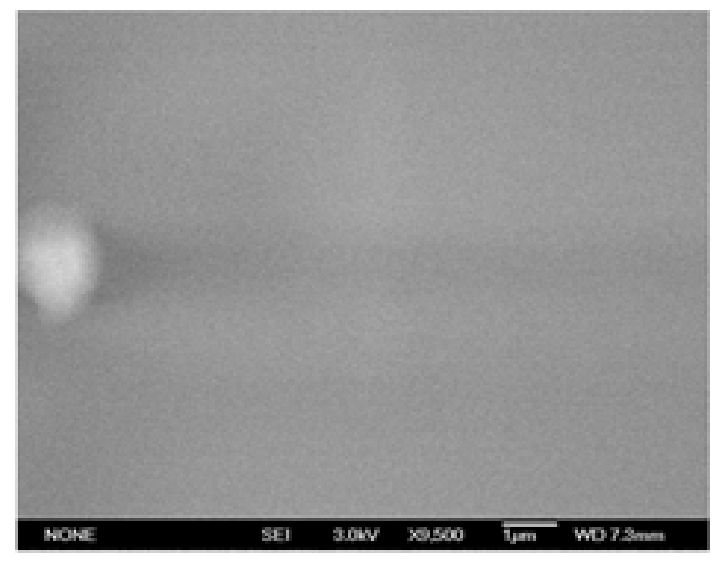

c

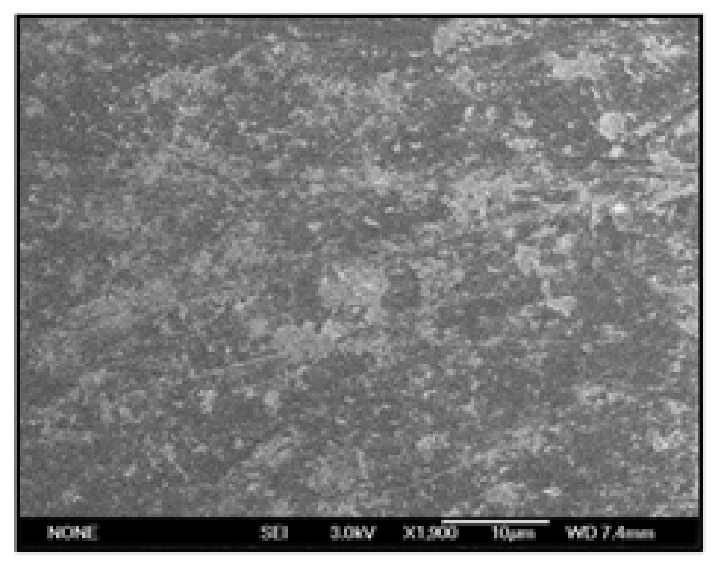

b

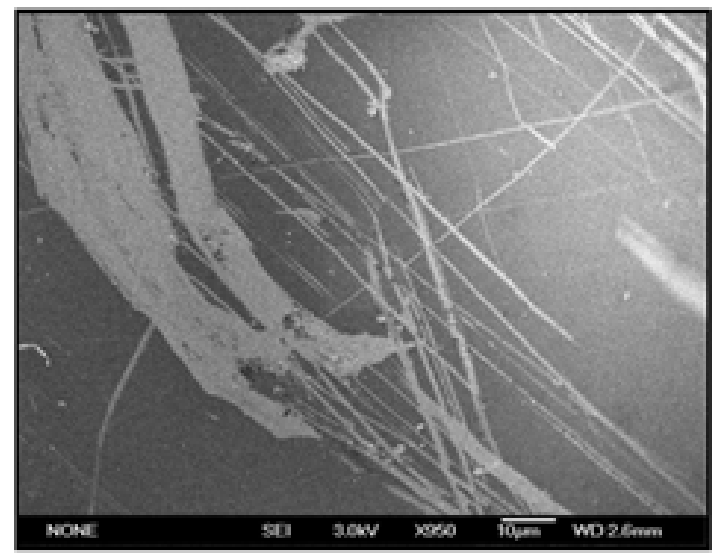

$\mathrm{d}$

Рис. 3. Изображения СЭМ пленок $\mathrm{BC}_{x} \mathrm{~N}_{y}$, полученных из паров ТЭАБ $(\mathrm{a}, \mathrm{b})$ и смеси ТЭАБ и $\mathrm{NH}_{3}(\mathrm{c}, \mathrm{d})$. Изображения до испытания (a) и (c), после испытания - (b) и (d).

Fig. 3. SEM images of $\mathrm{BC}_{x} \mathrm{~N}_{y}$ films obtained from TEAB vapor $(\mathrm{a}, \mathrm{b})$ and mixture of $\mathrm{TEAB}$ and $\mathrm{NH}_{3}(\mathrm{c}, \mathrm{d})$. Images before testing are (a) and (c), after testing are (b) and (d).

После обработки картины поверхности существенно зависели от состава пленок. Изображение пленки состава $\mathrm{BC}_{0.9} \mathrm{~N}_{0.4}$, полученной из ТЭАБ, после обработки имеет вид, качественно подобный тому, что наблюдался для пленок $\mathrm{SiC}_{x} \mathrm{~N}_{y} \mathrm{H}_{z}$ (рис. 3): появился контраст, обусловленный присутствием на поверхности уцелевших и разрушенных участков. В то же время, изображение пленки с большим содержанием азота состава $\mathrm{BC}_{0.3} \mathrm{~N}_{1.6}$, полученной из смеси ТЭАБ и $\mathrm{NH}_{3}$, после обработки демонстрирует наличие множества царапин (рис. 3). Для достижения наилучших условий наблюдения данного эффекта увеличение микроскопа было уменьшено в 10 раз. Известно, что при газоабразивном изнашивании относительный вклад механизмов разрушения через вдавливание и царапание зависит от угла атаки поверхности твердыми частицами [1]. Роль царапания повышается с уменьшением угла атаки, отсчитываемого от поверхности образца. В данной работе применялся угол атаки $45^{\circ}$, для которого нормальный и касательный компоненты скорости частиц равны. Следовательно, смена механизма разрушения пленки обусловлена изменением ее механических свойств. Ранее было показано, что при увели- чении содержания аммиака в составе исходной газовой смеси происходит рост концентрации азота в пленках $\mathrm{BC}_{x} \mathrm{~N}_{y}$, их состав изменяется от состава, близкого к карбиду бора до состава, близкого к нитриду бора. При этом уменьшаются твердость, модуль Юнга и плотность пленок $[9,13]$. Твердость и модуль Юнга пленок $\mathrm{BC}_{x} \mathrm{~N}_{y}$, синтезированных из газовой фазы, содержащей малую концентрацию аммиака, выше этих величин, характерных для диоксида кремния (частиц песка). При увеличении концентрации аммиака в исходной газовой смеси в процессе синтеза пленок $\mathrm{BC}_{x} \mathrm{~N}_{y}$ их твердость и модуль Юнга уменьшаются и приближаются к свойствам $\mathrm{SiO}_{2}$. По видимому, эта ситуация способствует преобладанию механизма царапания [1].

При интерпретации результатов подобных исследований необходимо принимать во внимание адгезионную прочность пленок. Наши исследования показали небольшую адгезию мягких полимероподобных пленок $\mathrm{SiC}_{x} \mathrm{~N}_{y} \mathrm{H}_{z}$ на кремнии, в то же время для пленок $\mathrm{BC}_{x} \mathrm{~N}_{y}$ характерна значительная адгезия. Полагаем, что полимероподобные пленки $\mathrm{SiC}_{x} \mathrm{~N}_{y} \mathrm{H}_{z}$ под действием твердых частиц отрываются от подложки, не только из-за раз- 
рушения по механизмам вдавливания и царапания, но и путем отслаивания. Пленки $\mathrm{BC}_{x} \mathrm{~N}_{y}$, в силу высокой адгезионной прочности, могут разрушаться только от вдавливания и царапания, при этом разумно ожидать увеличение роли царапания с уменьшением твердости пленок.

\section{4. Заключение}

Исследованы закономерности газоабразивного изнашивания пленок карбонитридов кремния и бора в условиях свободного падения частиц песка на поверхность. Обнаружено, что с ростом температуры осаждения в процессе PECVD и соответствующего изменения состава пленок от кремнийорганических $\mathrm{SiC}_{x} \mathrm{~N}_{y} \mathrm{H}_{z}$ к карбонитридным $\mathrm{SiC}_{x} \mathrm{~N}_{y}$, наблюдается увеличение газоабразивной износостойкости. Значения шероховатости и изменения спектров отражения обработанной поверхности уменьшаются при этом изменении состава. Изображения СЭМ показывают уменьшение относительной площади разрушенных областей.

Для пленок $\mathrm{BC}_{x} \mathrm{~N}_{y}$, полученных методом LPCVD из паров ТЭАБ и смеси ТЭАБ с аммиаком при отношении парциальных давлений $1: 1$, наблюдаются различные механизмы разрушения. При отсутствии аммиака в исходной газовой смеси картина аналогична характерной для пленок $\mathrm{SiC}_{x} \mathrm{~N}_{y}$, а при добавлении аммиака поверхность приобретает специфический вид с множеством царапин. Такие изменения связываются с уменьшением твердости и модуля Юнга пленок $\mathrm{BC}_{x} \mathrm{~N}_{y}$ из-за изменений их химического состава.

В завершение отметим, что на изображениях электронной или оптической микроскопии относительная площадь областей, имеющих контраст по сравнению с необработанной поверхностью, может служить эффективным критерием газоабразивного износа. Существуют компьютерные программы для обработки изображений, которые позволяют количественно определить величину этой площади. В дальнейшем планируется использование таких программ в практике исследования износостойкости пленок и покрытий.

Благодарность/Acknowledgements. Работа выполнена при финансовой поддержке Гранта Президента РФ № MK-7650.2016.8. This work was supported by the Russian Federation President Grant MK-7650.2016.8.

\section{Литература/References}

1. V.I. Biryukov, V.N. Vinogradov, M.M. Martirosyan, V.N. Mihaylychev. Abrasive wear of gas production equipment. Moscow, Nedra. (1977) 207 p. (in Russian) [В.И. Бирюков, В.Н. Виноградов, М. М. Мартиросян, В.Н. Михайлычев. Абразивное изнашивание газопромыслового оборудования. М.: Недра, 1977. 207 с.]

2. Energy from the Desert: Feasability of Very Large Scale Photovoltaic Power Generation (VLS-PV) Systems. Ed. by K. Kurokawa. New-York, Earthscan. (2013) 193 p.
3. H. Niederwald, S. Laux, M. Kennedy, U. Schallenberg, A. Duparré, M. Mertin, N. Kaiser, D. Ristau. Appl. Opt. 38(16), 3610 - 3613 (1999). doi: 10.1364/AO.38.003610.

4. P. H. Shipway, L.M. Hutchings. Wear. 193, 105-113 (1996). doi: 10.1016/0043-1648 (95) 06694-2.

5. K. Haugen, O. Kvernvold, A. Ronold, R. Sandberg. Wear. 186 - 187, 179 - 188 (1995), doi: 10.1016/0043 - 1648 (95) 07158-X.

6. B. A.Uryukov,G. V.Tkachenko.PowderMetall.Met.Ceram. 49, $581-587$ (2011), doi: 10.1007/s11106-011-9273-5. [Б. А. Урюков, Г. В. Ткаченко // Порошковая металлургия. 2010. № 9-10. С. 111 - 118.]

7. C.Y. Wong, Ch. Solnordal, A. Swallow, S. Wang, L. Graham, J.Wu. Wear. 276-277, 1 - 15 (2012). doi: 10.1016/j.wear.2011.11.005.

8. E.A. Sereda, V.G. Kopchenkov. Industrial laboratory. Diagnostics of materials. 72(10), 53-56 (2010) (in Russian) [Е.А. Середа, В.Г. Копченков. // Заводская лаборатория. Диагностика материалов. 2006. Т. 72. № 10. С. 53 - 56.]

9. M.L. Kosinova, N.I. Fainer, V.S. Sulyaeva, Yu. M. Rumyantsev, F. A. Kuznetsov, E. A. Maximovskii, Z. Cao, M. Terauchi, K. Shibata, F. Satoh. Proc. Fifteenth European Conference on Chemical Vapor Deposition (EUROCVD-15). 2005-09, 1082 - 1087 (2005).

10. V.R. Shayapov, M.N. Khomyakov, Yu. M. Rumyantsev. Letters on materials. 4(2), $114-116$ (2014).

11. V.R. Shayapov, Yu.M. Rumyantsev, N.I. Fainer, B. M. Ayupov. Russ. J. Phys. Chem. A. 86(11), 1714-1718 (2012), doi: 10.1134/S0036024412110258. [В. Р. Шаяпов, Ю. М. Румянцев, Н. И. Файнер, Б. М. Аюпов // Журнал физической химии. 2012. Т. 86. № 11. С. 1841 - 1846.]

12. V.R. Shayapov, Yu.M. Rumyantsev, P.E. Plyusnin. High Energ. Chem. 50(3), 213-218 (2016), doi: $10.1134 /$ S0018143916030127 [В.P. Шаяпов, Ю.М. Румянцев, П.Е. Плюснин // Химия высоких энергий. 2016. Т. 50. № 3. С. $221-226$.]

13. V.R. Shayapov, M.L. Kosinova, A.P. Smirnov, E. A. Maksimovskii, B. M. Ayupov, Yu. M. Rumyantsev. Inorg. Mater. 47(3), 262-266 (2011), doi: $10.1134 /$ S0020168511030204 [В.Р. Шаяпов, М. Л. Косинова, А.П. Смирнов, Е.А. Максимовский, Б. М. Аюпов, Ю. М. Румянцев // Неорганические материалы. 2010. Т. 47. № 3. С. 312 - 316.]

14. V.V. Atuchin, B.M. Ayupov, V.A. Kochubey, L.D. Pokrovsky, C.V. Ramana, Yu. M. Rumiantsev. Opt. Mater. 30(7), $1145-1148$ (2008), doi: 10.1016/j. optmat.2007.05.040.

15. B.M. Ayupov, Yu.M. Rumyantsev, V.R. Shayapov. J. Surf. Invest. 4(3), 452-457 (2010), doi: 0.1134/S1027451010030158. [Б.М. Аюпов, Ю. М. Румянцев, В.Р. Шаяпов // Поверхность. 2010. № 5. C. 100 - 105.]

16. B. M. Ayupov, I. A. Zarubin, V. A. Labusov, V. S. Sulyaeva, V.R. Shayapov. J.Opt. Technol. 78(6), 350-354 (2011), doi: 10.1364/JOT.78.000350. [Б.М. Аюпов, И. А. Зарубин, В. А. Лабусов, В. С. Суляева, В. Р. Шаяпов // Оптический журнал. 2011. Т. 78. № 6. С. 3 -9.] 